\title{
Learning strategy, list abstractness, and free-recall learning
}

GORDON WOOD and ROBERT H. TERBORG, Department of Psychology, Michigan State University, East Lansing, Mich. 48823

The influence of learning strategy and type of list (abstroct us concrete) were investigated in two experiments. The results of both experiments strongly indicated that instructions to link successive items facilitates free recall relative to rehearsal instructions. The control Ss were generally inferior to the Ss instructed to link successive words but superior to the rehearsal Ss. It was unclear whether the instruction effect depended on the type of list, but there was some evidence that the instruction effect increased as the number of learning trials increased.

There is only limited support for the view that instructions to use a particular strategy can influence the amount of free-recall learning. Eagle (1967) found no effect on recall due to strategy instructions even though Ss who reported that they attempted to associate the words recalled more than Ss who reported repeating the words during the learning trial. Wood (1967) was able to demonstrate that instructing Ss to link successive items can increase the recall of relatively high frequency concrete nouns. Allen (1968) showed that forcing Ss to spell each CVC aloud and continue spelling it repeatedly for the 2-sec presentation period impaired performance relative to control Ss allowed to use any strategy. The present study was a further attempt to demonstrate that learning strategy can influence the amount of free recall. The abstractness of the words to be recalled was also manipulated to assess whether the effect of learning strategy depends on the nature of the material to be recalled.

Instructions to associate or link successive items was expected to facilitate recall relative to uninstructed control Ss since there is considerable evidence (e.g., Tulving, 1968; Tulving \& Osler, 1967; Wood, in press) which suggests that the formation of associations among the items to be learned is a crucial aspect of free-recall learning. Since rehearsal instructions was expected to result in the formation of fewer or poorer associations among items, rehearsal Ss were expected to have lower performance than uninstructed control Ss.

Method

\section{EXPERIMENT 1}

A 3 by 2 factorial design was used with instructions and type of list (concrete vs abstract) as the two variables. Two of the groups were instructed to link successive words in the list during the learning trial. Two groups were instructed to repeat each word as it was presented and then repeat as many of the immediately preceding words as possible. Two groups were told to employ whatever strategy they chose. The 30 concrete words were randomly selected from the Underwood \& Richardson (1957) sensory impression norms. The 30 abstract words were randomly selected from the 120 abstract words listed by Gorman (1961). A total of 96 students enrolled in undergraduate psychology courses at Michigan State University were assigned equally to the six conditions.

The Ss were run in multiples of six so that all conditions were represented in any one session. Each $S$ was given a three page booklet consisting of a cover page, instruction page, and one answer sheet. The words were presented by means of a booklet having 30 pages ( $4 \frac{1}{4}$ in. $\times 5^{1 / 2}$ in.) plus a cover page. One word was printed in the middle of each page. Three groups received concrete words, and three groups received abstract words.

The Ss were given general instructions regarding the nature of the experiment and the use of the word booklet. Following the general instructions, the Ss were instructed to turn to the second page of their answer sheet booklet and read their special instructions. After each $S$ assured $E$ that they understood their instruetions the presentation of the word lists began. Every $5 \mathrm{sec}$ the $\mathrm{E}$ told the Ss to turn one page of their word booklet. This procedure was continued until the Ss had seen all the words. Following the presentation of the lists, the Ss were given $5 \mathrm{~min}$ to recall the words.

\section{Results and Discussion}

The mean number of words correctly recalled for the linking, control, and rehearsal conditions was $17.50,15.13$, and 13.38 , respeetively, for the concrete hist and 10.94, 12.88, and 9.88, respectively, for the abstract list. The List effect, $F=$ 32.79 , df $=1 / 90, p<.001$, and the Instruction effect, $F=$ 5.37 , df $=2 / 90, p<.01$, were both significant. A comparison of the Control and Rehearsal Groups revealed a significant superiority for the Control Groups, $F=7.32$, df $=1 / 90$, $p<.01$. Since the Linking Groups were just slightly superior (not significantly) to the Control Groups, it follows that the Linking Groups were also superior to the Rehearsal Groups. The significant Instructions by Type of List interaction, $F=$ 3.19 , df $=2 / 90, p<.05$, was due to the fact that the difference between the linking and control strategies was greater for the concrete than the abstract list, $F=5.72$, df $=$ $1 / 60, p<.05$. It appears that a linking strategy was more effective for concrete lists than for abstract lists.

In general the results supported the view that instructing Ss to rehearse or to link words influences their free-recall performance. However, it was not clear why Linking Groups did not recall significantly more words than the Control Groups. A simple explanation is that control Ss also attempted to link the items during the learning trial. Since Ss were not asked about the strategies they used, it was not possible to determine whether the Linking Groups and Control Groups differed regarding strategy. Another problem is that it was not clear why a linking strategy should be better for concrete than abstract words. Perhaps one trial did not afford the Ss in the linking-abstract condition sufficient opportunity to attempt their strategy, or Ss were unable to employ a linking strategy for the abstract list. To test these possibilities, a second experiment was conducted which was identical to Experiment 1 except that three free-recall trials were given and Ss were questioned regarding the strategies they employed.

\section{Method}

\section{EXPERIMENT 2}

A total of 90 students enrolled in undergraduate psychology courses at Michigan State University were assigned equally to the six conditions. The design and lists for Experiment 2 were essentially identical to Experiment 1 . The procedure differed in that three alternating study and test trials were given instead of only one study and test trial, and the Ss were given 2 min for each test trial. Following the Iast test trial, Ss were requested to report the strategy they used to recall the words. Due to an $E$ error, the information regarding strategy was 


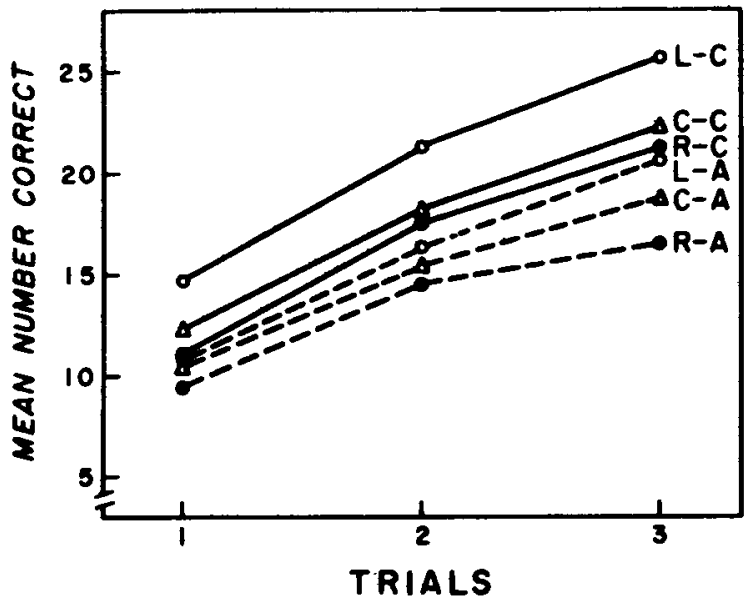

Fig. 1. The mean number of words correctly recalled for $\mathrm{Ss}$ who received linking (L), rehearsal (R), or control (C) instructions (denoted by the first letter) and abstract (A) or concrete (C) words (denoted by the second letter).

obtained for only 12 of the 15 Ss in each group.

Results and Discussion

The mean number of words correctly recalled for the three free-recall test trials is presented in Fig. 1. An analysis of the total number of words recalled revealed that the List, $F=$ 29.72, $\mathrm{df}=1 / 84, \mathrm{p}<.001$, and Instruction effect. $\mathrm{F}=8.38, \mathrm{df}$ $=2 / 84, p<.001$, were both significant. The Linking Groups were superior to the Rehearsal Groups, $F=16.37$, $\mathrm{df}=1 / 84$, $p<.001$, and the Control Groups, $F=6.54$, df $=1 / 84$, $p<.05$. The Rehearsal Groups and the Control Groups did not differ significantly, $F=2.21, \mathrm{df}=1 / 84, \mathrm{p}>.05$. Thus, the results of Experiment 2 were in agreement with Experiment 1 in demonstrating that instructions to employ particular strategies can influence the amount of recall. The control Ss and rehearsal Ss in Experiment 2 did not differ significantly whereas the control Ss and linking Ss did not differ significantly in Experiment 1 . The inconsistency between the two experiments was probably a function of a difference in the extent to which control Ss employed a linking strategy.

The number of $S$, out of a total possible of 24 , who reported using a linking strategy at least for the later stages of learning was 24,16 , and 8 for the linking, control and rehearsal instruction conditions, respectively. The eight $\mathrm{Ss}$ in the rehearsal condition indicated that they attempted the rehearsal strategy initially but then switched to a linking strattegy. If one assumes that Ss are more likily to give up an ineffietive strategy. the $S s^{*}$ reports suggest llat a linking strategy is superior to a rehearsal strategy. A post hoc division of the control Ss into linking and nonlinking groups was mate on the basis of their reports. Although the Ss who reported linking successive items had higher mean recall on Trial 3 for both the abstract and concrete lists, the differences were not significant. The failure to obtain significant differences was due. at least in part, to the small number of Ss involved.

The results of Experiment 2. unlike the results of Experiment 1, suggested that the influence of the instruction conditions does not depend on the type of list. The Lists by Instructions interaction was not significant when all three test trials were considered, $\mathrm{F}=1.06, \mathrm{df}=2 / 84, \mathrm{p}>.05$, or when only the first test trial was considered, $F=1.73$. $\mathrm{df}=2 / 84$, $p>.05$. Since an Instruction by List interaction was obtained in Experiment 1 but not in Experiment 2, it was not clear whether the instruction effect depended on the type of list.

There was some evidence that the instruction effect was greater for the later stages of learning. The differences between strategies tended to increase, particularly for Ss who received the abstract list, as indicated by the significant Instructions by Trials interaction, $F=2.43, \mathrm{df}=4 / 168, \mathrm{p}<.05$. To say this another way, the instruction effect for $S s$ who received the abstract list was not significant $(F<1)$ when Trial 1 was considered but for Trial 3 the strategy differences were significant, $F=3.97, \mathrm{df}=2 / 42, \mathrm{p}<.05$.

\section{REFERENCES}

ALLEN M. Rehearsal strategies and response cueing as determinants of organization in free recall. Journal of Verbal Learning and Verbal Behavior, 1968, 7, 58-63.

EAGLE, M. N. The effect of learning strategies upon free recall. A merican Journal of Psychology, 1967, 80, 421-425.

GORMAN, A. M. Recognition memory for nouns as a function of abstractness and frequency. Journal of Experimental Psychology, $1961,61,23-29$.

TULVING, E. Theoretical issues in tree recall. In T. R. Dixon and D. L. Horton (Eds.), Verbal behavior and general behavior theory. Englewood Cliffs, N. J.: Prentice-Hall, 1968, Pp. 1-36.

TULVING, E \& OSLER, S. Transfer effects in whole part free-recall learning. Canadian Journal of Psychology, 1967, 21, 253-262.

UNDERWOOD, B. J., \& RICHARDSON, J. Some verbal materials for the study of concept formation. Psychological Bulletin. 1956, 53, 84-95.

WOOD, G. Mnemonic systems in recall. Joumal of Educational Psychological Monographs, 1967, 58, (Whole No. 645).

WOOD, G. Whole-part transfer from free recall to serial learning. Journal of Experimental Psychology, in press. NOTE

1. This investigation was supported by Public Health Service Research Grant MH 14063 from the National Institute of Health. Thanks are due Joyce Pennington. 